https://doi.org/10.37208/tgn27115

\section{The collared earthstar (Geastrum triplex) in the Glasgow area, Scotland}

\author{
C.J. McInerny \\ School of Life Sciences, University of Glasgow, \\ Glasgow G12 8QQ \\ E-mail: chris.mcinerny@glasgow.ac.uk
}

The collared earthstar (Geastrum triplex) is a curious fungus with a distinctive mushroom fruiting body that is rare in Scotland. Here I report two observations of the species in the Glasgow area.

Eighteen species of earthstars of the genus Geastrum have been recorded in the U.K., but most are uncommon, with some on the Red Data List of Threatened British Fungi (Evans et al., 2006; Phillips, 2006; NBN Atlas, 2018). The genus has a southern distribution with only ten species recorded in Scotland, where all are rare. The collared earthstar is the most reported, but with a limited distribution: the NBN Atlas lists only 16 records, with the majority of these from the south-east of Scotland in Lothian, Edinburgh and the Scottish Borders (NBN Atlas, 2018). Just one record is assigned to west Scotland in Glasgow, from Govan on 17th November 2004. However, more records for west Scotland have been deposited at the Glasgow Museums Biological Records Centre (GMBRC) from up to 16 different

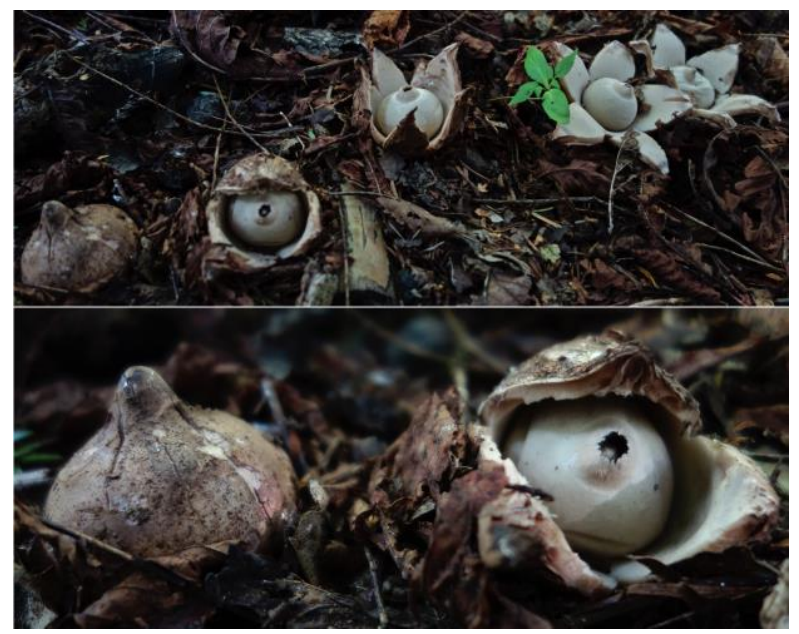

Fig. 1. Collared earthstars (Geastrum triplex), Baron's Haugh, Motherwell, North Lanarkshire, September 2015, showing the stages of the fruiting body development and emergence. The bulbs are $3-5 \mathrm{~cm}$ in diameter, and the stars $5-10 \mathrm{~cm}$. (Photos: C.J. McInerny) locations across Glasgow, all since 2007, mostly in public parks. It appears that the fungus first appeared in Glasgow about 14 years ago, with a subsequent spread across the city, although this apparent trend may in part reflect observer effort.

Such a restricted Scottish distribution is surprising as the species has a widespread and cosmopolitan range, being found on all continents around the world apart from Antarctica, and being common in some areas, including England (Jordon, 2004). However, recent genetic studies reveal that a taxonomic revision is required as taxa identified as G. triplex from different continents are polyphyletic, not sharing a common ancestor, suggesting that instead multiple species are involved (Kasuya et al., 2012).

The collared earthstar is a saprotrophic fungus, obtaining nutrients and energy from decaying matter such as leaf-litter, detritus and humus. In Europe it is usually found on deciduous forest floors, often associated with beech trees (Fagus sylvatica), with the mushroom fruiting bodies visible above ground from late summer to late autumn.

The mushroom fruiting body of collared earthstar is distinctive in shape and appearance (Figs. 1-3). When first erupting above ground it is brown and bulb-shaped, $3-5 \mathrm{~cm}$ in diameter (Fig. 1). On development the bulb splits, with the outer layer forming four to eight pointed spongy white rays, $5-10 \mathrm{~cm}$ in diameter, revealing a similarly pale spore-sac, creating the earthstar (Fig. 2). The rays subsequently bend back underneath the fruiting body, leaving the spore-sac on a saucer-shaped base (Fig. 3).

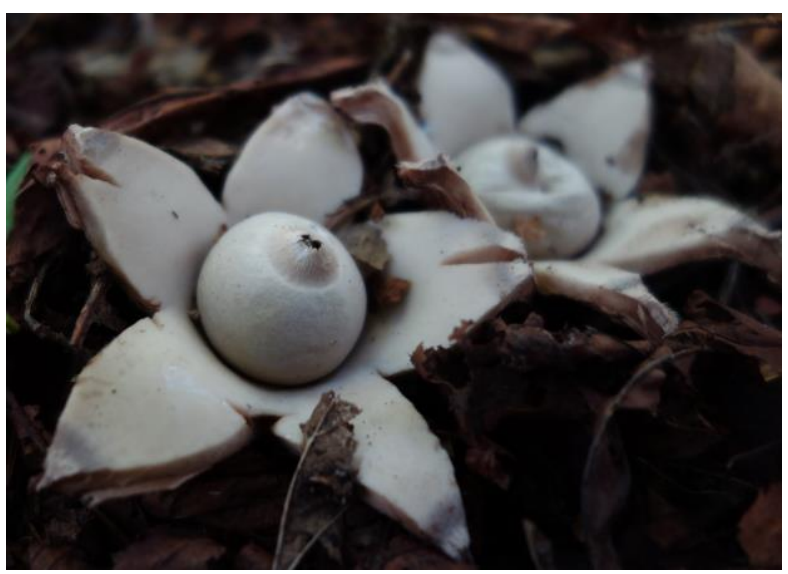

Fig. 2. Fully opened collared earthstars (Geastrum triplex), Baron's Haugh, Motherwell, North Lanarkshire, September 2015. The stars are $5-10 \mathrm{~cm}$ in diameter. (Photo: C.J. McInerny) 


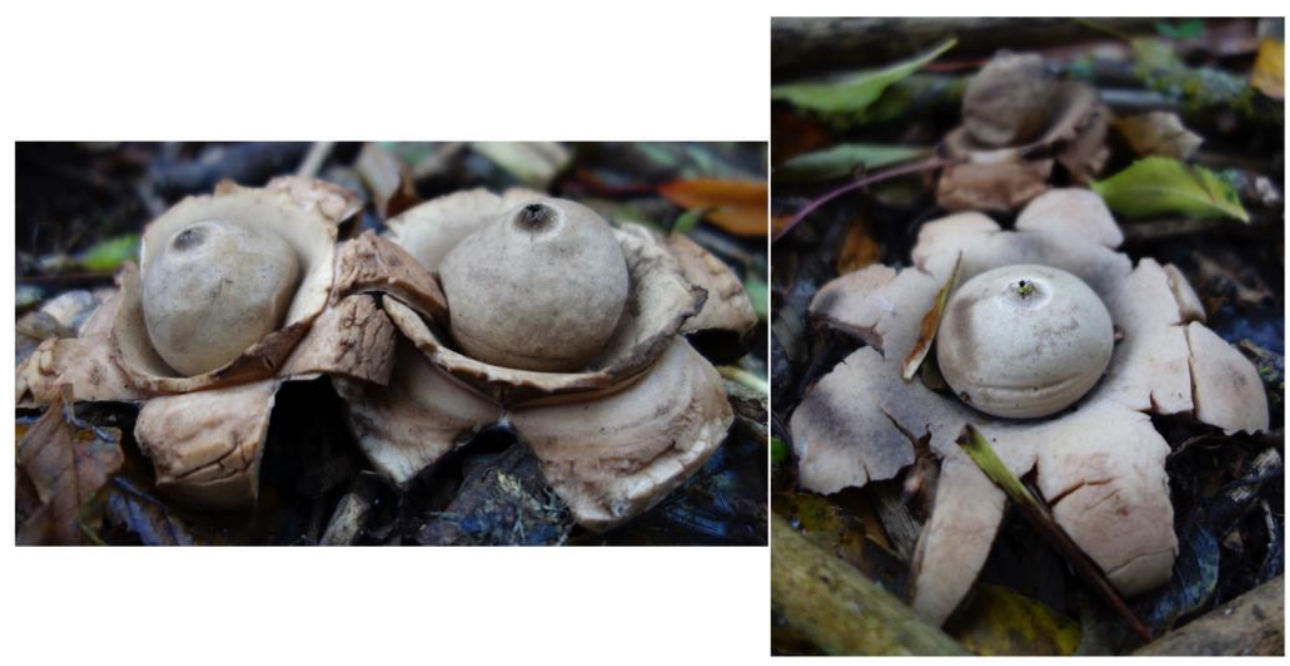

Fig. 3. Fully developed collared earthstars (Geastrum triplex), Victoria Park, Glasgow, October 2018. The stars are 5-10 cm in diameter. (Photos: C.J. McInerny)

Two new sites in the Glasgow area have collared earthstars, which have been fruiting for a number of years, one since at least 2015. The first site is at Baron's Haugh, Motherwell, North Lanarkshire (NS755551), with the fungi under pine trees (Pinus sp.) in mixed woodland (Figs. 1, 2). The second site is in Victoria Park, Glasgow (NS541672), amongst shrubs and trees adjacent to a children's play area (Fig. 3).

The species could be found elsewhere in west Scotland. It is hoped that publishing this note will alert observers to the distinctive appearance of the collared earthstar allowing others to find this beautiful fungus in new locations.

\section{ACKNOWLEDGEMENTS}

I thank Davie Abraham for alerting me to the earthstars in Motherwell, and Myles O'Reilly those in Victoria Park; and to GMBRC for other Glasgow records. Thanks to an anonymous reviewer for improvements to the text.

\section{REFERENCES}

Evans, S., Henrici, A. \& Ing, B. (2006). Red Data List of Threatened British Fungi. British Mycological Society.

www.britmycolsoc.org.uk/mycology/conservation/r ed-data-list

Jordon, M. (2004). The Encyclopedia of Fungi of Britain and Europe. Frances Lincoln, London.

Kasuya, T., Hosaka, K., Uno, K. \& Kakishima, M. (2012). Phylogenetic placement of Geastrum melanocephalum and polyphyly of Geastrum triplex. Mycoscience 53, 411-426.

https://doi.org/10.1007/S10267-012-0186-Z

National Biodiversity Network (NBN) Atlas (2018). www.nbnatlas.org Accessed 24 October 2018.

Phillips, R. (2006). Mushrooms. Pan MacMillan, London. 